\title{
Beliefs and Clinical Practice for Complex Regional Pain Syndrome (CRPS) Managed by Physiotherapists on the South Island of New Zealand
}

\author{
Tracey Pons ${ }^{1 *}$, Edward A. Shipton ${ }^{1}$, Roger T. Mulder ${ }^{2}$ \\ ${ }^{1}$ Department of Anaesthesia, University of Otago, Christchurch, New Zealand \\ ${ }^{2}$ Department of Psychological Medicine, University of Otago, Christchurch, New Zealand \\ Email: tracey@paintherapy.co.nz, shiptonea@xtra.co.nz,roger.mulder@otago.ac.nz
}

How to cite this paper: Pons, T., Shipton, E.A. and Mulder, R.T. (2017) Beliefs and Clinical Practice for Complex Regional Pain Syndrome (CRPS) Managed by Physiotherapists on the South Island of New Zealand. International Journal of Clinical Medicine, 8, 42-54. http://dx.doi.org/10.4236/ijcm.2017.81005

Received: November 30, 2016

Accepted: January 21, 2017

Published: January 24, 2017

Copyright ( 92017 by authors and Scientific Research Publishing Inc. This work is licensed under the Creative Commons Attribution International License (CC BY 4.0).

http://creativecommons.org/licenses/by/4.0/ (c) (i) Open Access

\begin{abstract}
On the South Island of New Zealand, Anaesthetists and other Medical Professionals, frequently refer their patients with Complex Regional Pain Syndrome (CRPS) for physiotherapy management. Beliefs about what is important for the management of patients with CRPS are lacking across all medical and allied health disciplines. Difficulties are no gold standard for diagnosis and evidence for intervention methods is moderate or can be conflicting. This paper explores what Physiotherapists believe to be important in a clinical setting for their management of CRPS, as well as documenting and evaluating their interventional methods used in everyday clinical practice across the region of the South Island of New Zealand. This has not been recorded before. Eightyone Physiotherapists replied to questions on their usual treatment interventions for the management of CRPS, their frequency of use of these treatment interventions, and what they believed to be important in the management of pain and improvement of function. The results demonstrated that CRPS is not a common condition seen regularly by Physiotherapists; that there is a high level of variation between the physiotherapy interventions used and that Physiotherapists' beliefs regarding interventions used for pain management and functional restoration differ. Education was reported as the most frequently used intervention method. Those physiotherapists seeing CRPS patients more frequently are more likely to use evidence based intervention methods like graded motor imagery or sensory motor training.
\end{abstract}

\section{Keywords}

Physiotherapy, Anaesthetists in Pain Management, Complex Regional Pain Syndrome (CRPS), Beliefs, Management, Intervention Methods, Outcomes 


\section{Introduction}

Complex Regional Pain Syndrome (CRPS) is a persistent pain syndrome with a low prevalence [1] [2] which exhibits abnormal sensory, motor, sudomotor, vasomotor, and/or trophic findings and shows variable progression over time [3] [4] [5] [6]. It is evaluated by anaesthetists in Pain Management or by physiotherapists. It can be argued that it is both under-diagnosed [7] and over-diagnosed [8] [9]. Early diagnosis and referral by anaesthetists in Pain Management or by other medical disciplines to physiotherapists is regarded as essential [10]. Unresolved issues remain. There is no gold standard for the management of CRPS. Contrasting interventional methods exist in the literature around improving functional ability or controlling the pain experience. Beliefs about what is important or not for the management of CRPS remain unknown.

In other domains, beliefs held by Medical Practitioners and Allied Health Professionals are shown to affect practice, for example, as follows: the pain experienced in the elderly can be minimised [11]; physiotherapists will continue to treat low back despite any evidence of improvement [12]; and beliefs about opioid medication affect prescription practice [13] [14].

Amongst physiotherapists two opposing beliefs exist regarding pain modulation or pain exposure. Pain modulation is supported by the evidence for Graded Motor Imagery (GMI) [15] [16], mirror exercise [17], Sensory-Motor Training (SMT) [18], Graded Exposure (GEXP) [19], relaxation [20], psychological techniques [21] and Transcutaneous Nerve Stimulation (TENS) [22]. Pain Exposure (PEXP) is supported by the evidence for progressive exercise loading without analgesia moving towards restoration of function [15] [23] [24]. The beliefs of Medical Practitioners or Allied Health Professionals on the management of CRPS are not documented.

\section{Purpose}

Beliefs about what Physiotherapists in a clinical setting regard as important for their management of CRPS, as well as their beliefs about the interventional methods used in everyday clinical practice across the region of the South Island of New Zealand were evaluated.

\section{Method}

There are 150 private practices and hospital outpatient departments listed across the South Island of New Zealand by the New Zealand Physiotherapy Society (PNZ). Physiotherapy staff numbers in these practices or clinics vary from solo practitioners to those with high staff numbers. Each individual practice or clinic was contacted to find out whether they accepted CRPS patients or not. Those accepting CRPS patients were asked to fill in a paper-based questionnaire about their usual physiotherapy management for CRPS, and what they believed to be important in the management of pain and for the function in these patients. Ethical approval for this study was provided by the University of Otago Ethics 
committee (Reference number H13/103). Inclusion criteria were a registered Physiotherapist currently working in any setting on the South Island of New Zealand who also accepted treating CRPS patients. Exclusion criteria were a registered Physiotherapist who never saw CRPS patients.

The questionnaire given to the Physiotherapist contained four sections. The first section asked how frequently CRPS patients were treated by them. A Likert Scale containing the following information was used: never; seldom (2 - 5 times per year); occasionally (5 - 10 times a year); regularly ( 2 - 3 times per month); or often (more than 5 times per month. The second section asked about the precise interventions carried out and their frequency of use. A Likert scale containing the following information was used, such as: never use this; occasionally use this; often use this; or most often use this. The third section enquired about what unlisted interventions the Physiotherapist used and their frequency of use. The fourth section looked at the beliefs the Physiotherapist held about the management of CRPS. The belief choice was as follows: reducing the pain is essential to improve the function; improving the function is essential to reduce the pain; exercising and increasing pain is contra-indicated; and exercising and increasing pain is indicated.

\section{Statistical Analysis}

Standard descriptive statistics (Statistica 7, Microsoft Excel for windows PC) was used to compare categorical variables. Data analysis used ANOVA tests for significance between categorical variables and frequency of consultations with Physiotherapists.

\section{Results}

The 64 clinics and hospital outpatient departments who accepted patients with CRPS employed a total of 141 Physiotherapists. The 84 clinics and hospital outpatient departments who did not accept CRPS patients were excluded from the sample. Questionnaires were posted in self-addressed and pre-stamped envelopes (one for each Physiotherapist), or personally delivered. Eighty-one Physiotherapists answered the questionnaire and returned it either personally $(n=5)$ or by mail $(n=76)$. This provided a response rate of $57 \%$. Participation rate in the physiotherapy intervention questionnaire is shown in Figure 1.

Eighty six (57.3\%) of the 150 physiotherapy practices or outpatient clinics contacted never accepted any CRPS patients and were not asked to participate in the study. The 81 Physiotherapists who treated patients with CRPS came from 64 (or $43 \%$ ) of the clinics and hospital outpatient departments across the South Island of New Zealand. Seven (or 4\%) of the 150 clinics contacted accepted patients with CRPS declined to answer the questionnaire. Reasons given were as follows: no reason given $(n=1)$; about to retire $(n=1)$; staff shortages $(n=1)$; unwilling to have practice scrutinised $(n=2)$; too busy $(n=1)$; or an assessment only service $(n=1)$.

Sixty-three per cent of this sample of Physiotherapists on the South Island 
who accepted patients with CRPS treated them infrequently (2 to 5 times annually). Twenty per cent treated 5 to 10 CRPS patients annually. Only $1 \%$ of Physiotherapists treated more than 5 CRPS patients in a month; $9 \%$ of Physiotherapists treated 2 - 3 CRPS patients each month. These data were simplified into two categories. Ninety per cent of Physiotherapists were categorised as seldom treating CRPS patients (less than 2 CRPS patients per month). Ten per cent of Physiotherapists were categorised as more frequently treating CRPS patients (more than 2 CRPS patients per month).

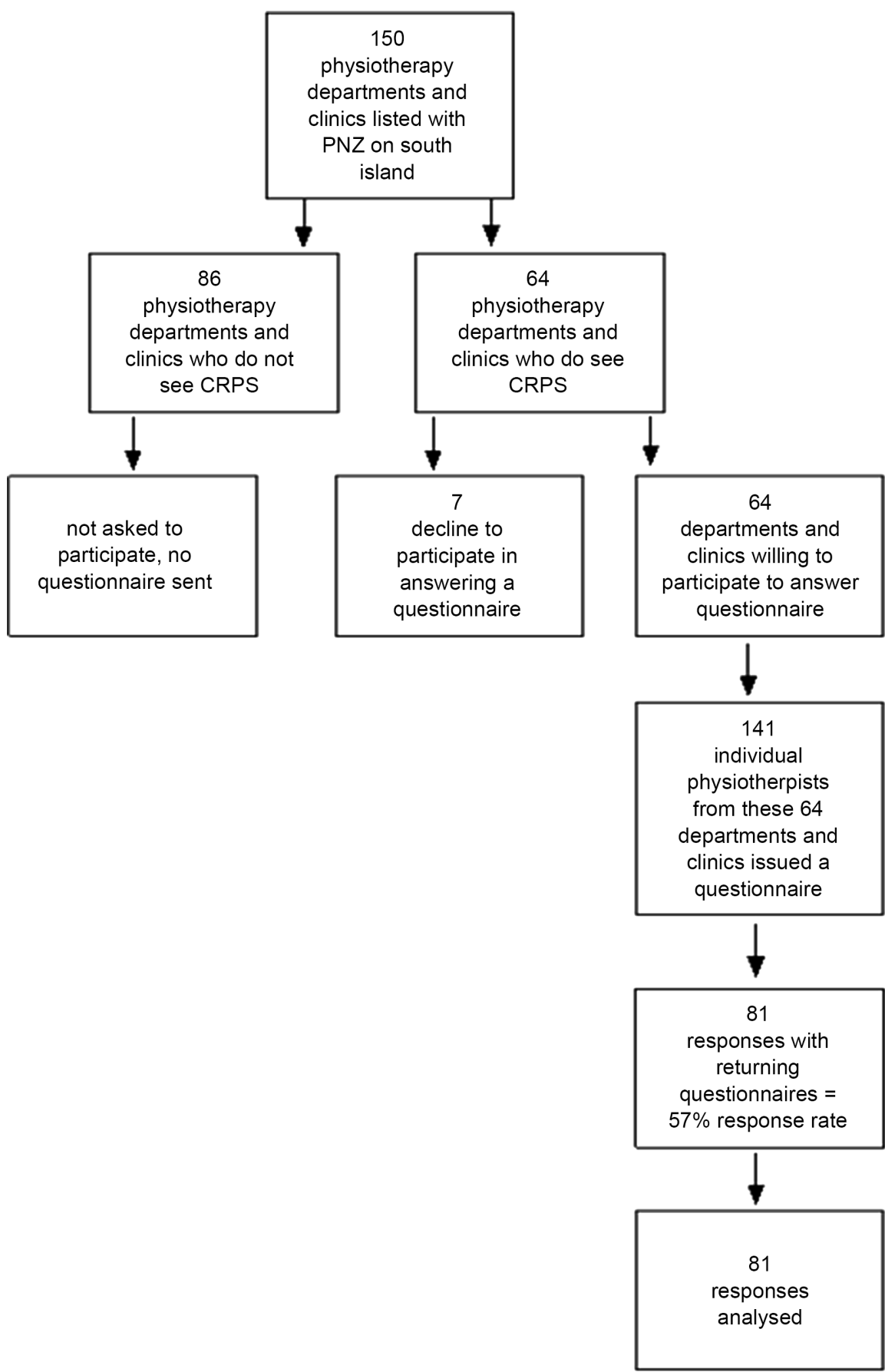

Figure 1. Participation with the physiotherapy intervention questionnaire. 
The routine physiotherapy interventions examined were as follows: active exercises within pain limits; active exercises despite pain; resisted exercises despite pain; eccentric exercises; pain exposure exercises; graded exposure exercises; education; passive exercises within pain limits; passive exercises despite pain; pool exercises; neural stretches; tendon glides; balance exercises; proprioceptive exercises; lymphoedema massage; oedema massage; prescribed homework; scheduled as time contingent or pain contingent; sensory mapping training; discrimination training; desensitising training; GMI in classic order; GMI in ad hoc order; mirror exercises; prism exercises; relaxation exercises; breathing control; cognitive techniques for pain control; problem solving techniques for pain control; cognitive behavioural therapy (CBT); acceptance and commitment therapy (ACT); iontophoresis; soft tissue mobilisation; trigger point release; and other interventions (not listed). Fifteen Physiotherapists used acupuncture.

Education was the modality most commonly used as an intervention for CRPS (83\% of Physiotherapists). Proprioceptive training and desensitising were often used (58\% of the Physiotherapists). Forty nine percent of physiotherapists applied active exercise despite pain occasionally; active and resisted exercises within pain limits were used by $41 \%$ and $42 \%$ of the Physiotherapists, respectively. The types of interventions listed as occasionally used by the largest groups were trigger points release (53\%), active exercise despite pain (49\%), pool exercise (44\%), and soft tissue mobilisation (41\%). On the other hand, Physiotherapists (88\%) seldom used iontophoresis, acupuncture (81\%), prism exercise (78\%), or acceptance and commitment therapy (70\%).

The frequency of use of all interventions used is listed in Table 1.

In the group who mostly used GMI, $10 \%$ used it in the classic order versus $2 \%$ who used it in an ad hoc sequence. However, $43 \%$ never used a GMI classic sequence at all. Twenty per cent occasionally used the GMI classic sequence. Fifteen percent of the GMI users often applied the classic sequence. Ten percent of Physiotherapists used the classic sequence of GMI as the most common intervention. Those who used the ad hoc sequence showed similar figures. This is shown in Figure 2.

These data were further analysed using ANOVA tests for significance to determine if the frequency of seeing CRPS patients affected the type of intervention used. The more frequently a Physiotherapist evaluated CRPS patients, the following occurred, namely: 1) they used GMI more often rather than occasionally in the classic order of the 3 phases, $p=0.017 ; 2$ ) the more they used relaxation techniques often rather than occasionally, $\mathrm{p}=0.021 ; 3$ ) the more likely they were to use SMT, and sensory mapping or discrimination occasionally rather than never, $\mathrm{p}<0.001$ and; 4) the more often they used oedema massage rather than seldom, $\mathrm{p}=0.029$. Table 2 outlines the significant differences between those Physiotherapists who evaluated CRPS patients frequently compared to those who seldom saw CRPS patients. 
Table 1. Physiotherapy interventions for CRPS and frequency of use.

\begin{tabular}{|c|c|c|c|c|c|}
\hline \multirow{2}{*}{ Intervention method } & \multirow{2}{*}{$\begin{array}{c}\text { Answered question } \\
\mathrm{N}(\%)\end{array}$} & \multicolumn{4}{|c|}{ Frequency of use by Physiotherapist (\% valid answers) } \\
\hline & & Never & Occasionally & Often & Mostly \\
\hline Active exercise within pain limit & $77(95 \%)$ & $0 \%$ & $14 \%$ & $41 \%$ & $41 \%$ \\
\hline Active exercise despite pain & $76(94 \%)$ & $20 \%$ & $49 \%$ & $20 \%$ & $5 \%$ \\
\hline Resisted exercise within pain limit & $74(91 \%)$ & $2 \%$ & $33 \%$ & $42 \%$ & $14 \%$ \\
\hline Resisted exercise despite pain & $73(89 \%)$ & $38 \%$ & $40 \%$ & $11 \%$ & $0 \%$ \\
\hline Eccentric exercise & $72(89 \%)$ & $38 \%$ & $40 \%$ & $11 \%$ & $0 \%$ \\
\hline Pain exposure exercise & $65(80 \%)$ & $30 \%$ & $32 \%$ & $11 \%$ & $7 \%$ \\
\hline Graded exposure exercise & $69(85 \%)$ & $11 \%$ & $20 \%$ & $33 \%$ & $21 \%$ \\
\hline Education & $79(98 \%)$ & $0 \%$ & $1 \%$ & $14 \%$ & $83 \%$ \\
\hline Passive exercise within pain limits & $71(88 \%)$ & $9 \%$ & $32 \%$ & $30 \%$ & $17 \%$ \\
\hline Passive exercise despite pain & $71(88 \%)$ & $36 \%$ & $37 \%$ & $11 \%$ & $2 \%$ \\
\hline Pool exercise & $76(94 \%)$ & $22 \%$ & $44 \%$ & $20 \%$ & $7 \%$ \\
\hline Neural stretches & $72(91 \%)$ & $11 \%$ & $43 \%$ & $33 \%$ & $4 \%$ \\
\hline Tendon glides & $72(91 \%)$ & $19 \%$ & $36 \%$ & $32 \%$ & $2 \%$ \\
\hline Balance exercise & $73(89 \%)$ & $9 \%$ & $22 \%$ & $51 \%$ & $9 \%$ \\
\hline Proprioceptive Exc & $86(94 \%)$ & $2 \%$ & $20 \%$ & $58 \%$ & $14 \%$ \\
\hline Lymphoedema massage & $73(90 \%)$ & $48 \%$ & $36 \%$ & $5 \%$ & $1 \%$ \\
\hline Oedema massage & $86(95 \%)$ & $25 \%$ & $42 \%$ & $20 \%$ & $9 \%$ \\
\hline Prescribed Homework: Scheduled as time contingent & $85(93 \%)$ & $6 \%$ & $22 \%$ & $48 \%$ & $16 \%$ \\
\hline Prescribed Homework: Scheduled as pain contingent & $85(93 \%)$ & $25 \%$ & $36 \%$ & $19 \%$ & $14 \%$ \\
\hline Sensory mapping training & $70(86 \%)$ & $42 \%$ & $32 \%$ & $12 \%$ & $1 \%$ \\
\hline Discrimination training & $74(91 \%)$ & $40 \%$ & $28 \%$ & $19 \%$ & $5 \%$ \\
\hline Desensitising training & $76(94 \%)$ & $2 \%$ & $20 \%$ & $58 \%$ & $14 \%$ \\
\hline Graded Motor Imagery (GMI) in classic order & $71(90 \%)$ & $43 \%$ & $20 \%$ & $15 \%$ & $10 \%$ \\
\hline GMI in your own order or ad hoc & $73(90 \%)$ & $44 \%$ & $27 \%$ & $16 \%$ & $2 \%$ \\
\hline Mirror exercise & $78(96 \%)$ & $21 \%$ & $31 \%$ & $35 \%$ & $10 \%$ \\
\hline Prism exercise & $69(85 \%)$ & $78 \%$ & $7 \%$ & $0 \%$ & $0 \%$ \\
\hline Relaxation exercises & $73(90 \%)$ & $11 \%$ & $33 \%$ & $33 \%$ & $12 \%$ \\
\hline Breathing control & $75(93 \%)$ & $12 \%$ & $33 \%$ & $33 \%$ & $14 \%$ \\
\hline Cognitive techniques for pain control & $73(90 \%)$ & $22 \%$ & $33 \%$ & $26 \%$ & $9 \%$ \\
\hline Problem solving techniques for pain control & $74(91 \%)$ & $20 \%$ & $31 \%$ & $25 \%$ & $16 \%$ \\
\hline Cognitive Behavioural Therapy (CBT) & $72(89 \%)$ & $48 \%$ & $15 \%$ & $22 \%$ & $4 \%$ \\
\hline Acceptance and Commitment Therapy (ACT) & $68(84 \%)$ & 705 & $9 \%$ & $4 \%$ & $1 \%$ \\
\hline Transcutaneous Electrical Nerve Stimulation (TENS) & $73(90 \%)$ & $21 \%$ & $44 \%$ & $23 \%$ & $1 \%$ \\
\hline Iontephoresis & $71(90 \%)$ & $86 \%$ & $0 \%$ & $1 \%$ & $0 \%$ \\
\hline Soft tissue mobilisation & $74(91 \%)$ & $9 \%$ & $41 \%$ & $37 \%$ & $5 \%$ \\
\hline Trigger point release & $73(90 \%)$ & $11 \%$ & $53 \%$ & $26 \%$ & $0 \%$ \\
\hline Acupuncture & $81(100 \%)$ & $81 \%$ & $9 \%$ & $11 \%$ & $0 \%$ \\
\hline
\end{tabular}




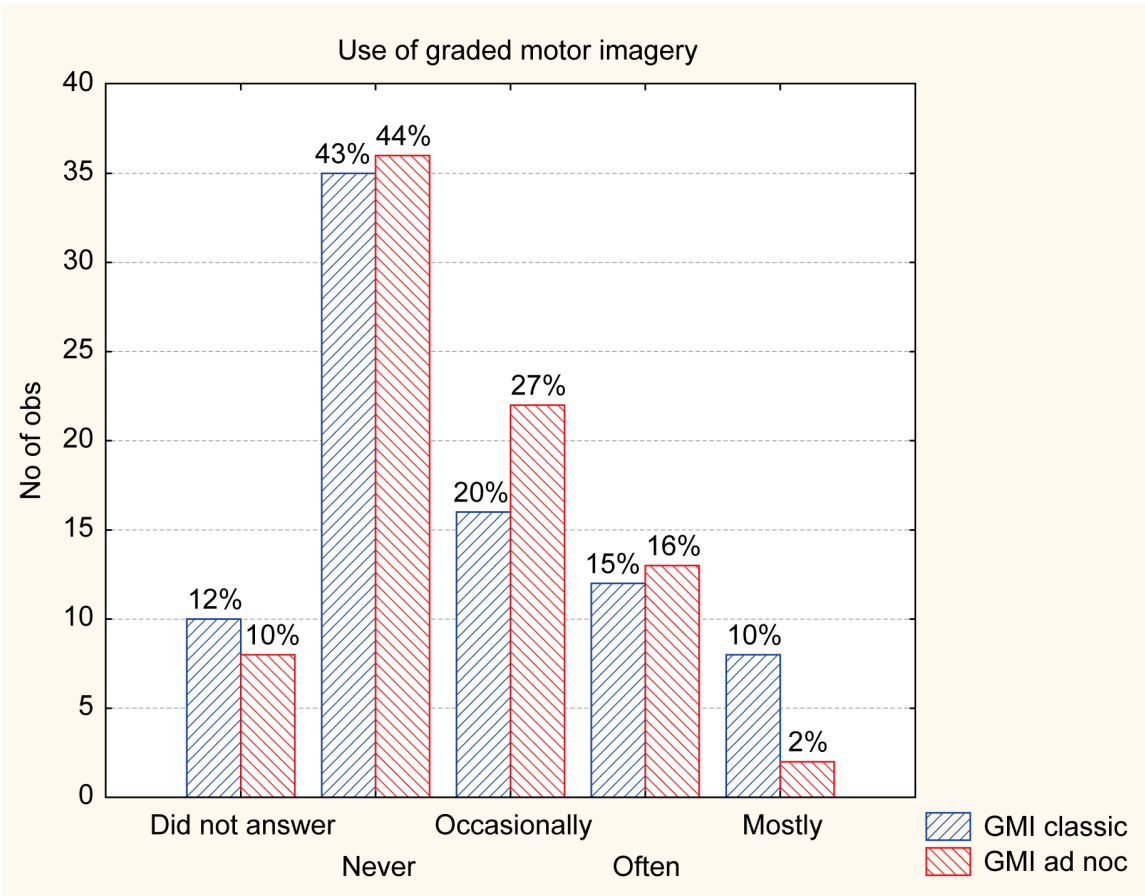

Figure 2. Use of graded motor imagery in clinical physiotherapy practice.

Table 2. Significant differences between those Physiotherapists who saw CRPS seldom versus those who saw CRPS patients often.

\begin{tabular}{lll}
$\begin{array}{c}\text { Physiotherapy intervention method more } \\
\text { likely to be used by the physio who sees } \\
\text { CRPS patients more often }\end{array}$ & Frequency of use more likely & P value \\
\hline Graded Motor Imagery (GMI) & From occasional to often & 0.017 \\
Relaxation techniques & From occasional to often & 0.021 \\
Sensory-Motor training (SMT) & & \\
- Sensory mapping & From never to occasional & 0.007 \\
- Discrimination & From never to occasional & 0.007 \\
- Desensitising & - From occasional to often & 0.007 \\
Oedema massage & From seldom to often & 0.029 \\
\hline
\end{tabular}

Beliefs about what was considered most effective for the management of CRPS patients proved highly variable. Physiotherapists were almost equally divided about whether or not reducing the pain experience was essential to improve the functioning ( $51 \%$ and $43 \%$, respectively). This is shown in_Figure 3 .

Eighty per cent believed that improving the function was essential to reduce pain; 14\% believed that it was not essential. This is shown in Figure 4.

Physiotherapists were equally divided on their beliefs about exercise and pain being either indicated or contraindicated in CRPS. These beliefs are shown in Figure 5.

The beliefs were summarised and are represented in Table 3. 
Table 3. Summary of Physiotherapist beliefs about what is best for CRPS intervention method.

\begin{tabular}{|c|c|c|c|}
\hline \multicolumn{4}{|c|}{ Physiotherapist beliefs about what is best for CRPS intervention method } \\
\hline & Did not answer & Yes & No \\
\hline & $\mathrm{n}(\%)$ & n $(\%)$ & $\mathrm{n}(\%)$ \\
\hline $\begin{array}{l}\text { Reducing the pain is essential } \\
\text { to improve the function }\end{array}$ & $5(6 \%)$ & $35(43 \%)$ & $41(52 \%)$ \\
\hline $\begin{array}{l}\text { Improving the function is essential } \\
\text { to reduce the pain }\end{array}$ & $5(6 \%)$ & $65(80 \%)$ & $11(14 \%)$ \\
\hline $\begin{array}{l}\text { Exercising and increasing the } \\
\text { pain is contraindicated }\end{array}$ & $6(7 \%)$ & $17(21 \%)$ & $58(72 \%)$ \\
\hline $\begin{array}{l}\text { Exercising and increasing the } \\
\text { pain is indicated }\end{array}$ & $6(7 \%)$ & $14(17 \%)$ & $61(75 \%)$ \\
\hline
\end{tabular}

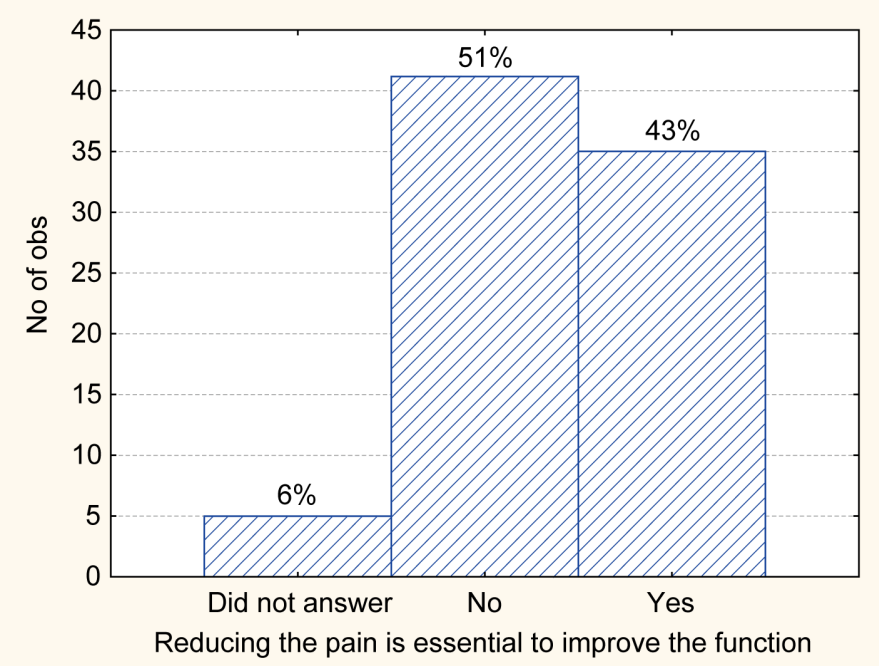

Figure 3. The belief about reducing the pain being essential in CRPS to improve the functioning.

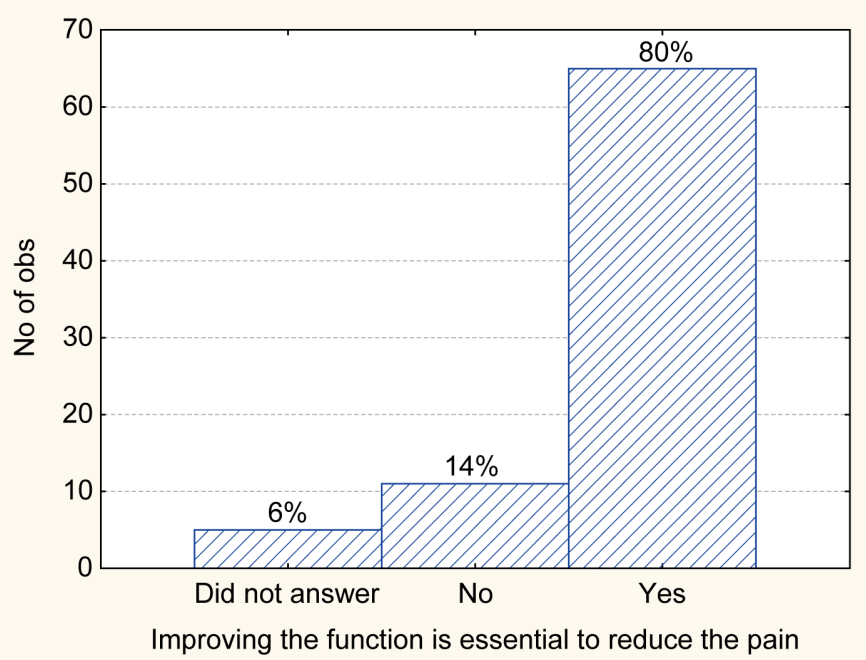

Figure 4. Improving the function is essential in order to reduce the pain experience. 


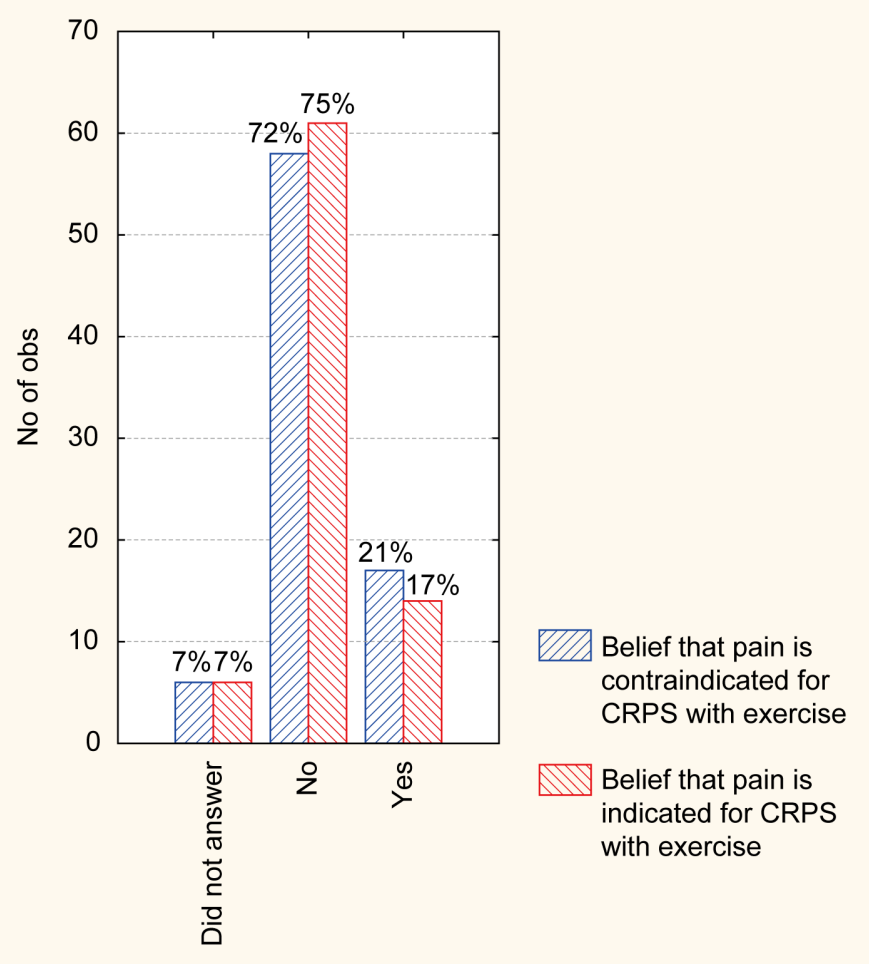

Figure 5. Beliefs about exercise and increasing pain being indicated or not for CRPS.

\section{Discussion}

These data provide the first contribution to literature about a systematic survey of physiotherapy and CRPS management in everyday clinical practice. Half of all New Zealand South Island physiotherapy practices do not manage CRPS patients. Only $10 \%$ of the Physiotherapists that manage CRPS patients treat more than two CRPS patients per month. Education was most often used as an intervention for CRPS. This was recorded by $83 \%$ of the Physiotherapists who together with Anaesthetists play an important role in education as CRPS patients possess a sub-minimum standard of basic knowledge about the syndrome [25]. Similar to diseases like diabetes, education enables behavioural change as well [26].

The data showed that the more frequently Physiotherapists evaluated CRPS patients, the more likely they were to use interventions with moderate based evidence, such as GMI and SMT. However, GMI and SMT were not used by many other Physiotherapists who evaluate CRPS patients less frequently. It is not possible to determine the reasons for these differences. This clearly needs further investigation. It has been suggested that physiotherapy management for CRPS needs to be specifically personalised [27]. This can be particularly difficult, as CRPS presentations, progression and outcome are variable. There is little specific evidence about what intervention to apply and when [28]?

These data illuminated the inconsistency with which physiotherapy interventions (other than education that is mostly used) are practised by those managing CRPS patients. A third of the sample often used cognitive techniques and 
breathing control with relaxation techniques; another third used them occasionally. Those treating more CRPS patients are more likely to use the above technique rather than occasionally. Less than $15 \%$ are most likely to use these techniques. Eighty per cent are familiar with these interventions but do not apply them regularly.

Beliefs were divided about pain reduction being essential or not for improving the function of the affected CRPS limb. Eighty per cent believed that by improving function, the pain is reduced. Exercising and increasing the pain was a belief supported by $17 \%$. It was found that $49 \%$ applied active exercises despite pain, but then only occasionally. When asked whether pain was contra-indicated or not for CRPS exercises, the groups were almost equally divided. Half believed that it was inevitable to have some pain with exercise; only $17 \%$ of this group believed that pain with exercise was really necessary.

Holding different beliefs influences the interventional modalities chosen for pain reduction or improvement in function for the treatment of CRPS patients. It influences the relationship the Physiotherapist has with the referring Anaesthetist. Applying any intervention by one half of Physiotherapists can become potentially difficult, if pain exacerbation is thought to be contraindicated, as pain forms the hallmark of CRPS. There are CRPS patients who present with reasonable function, but suffer severe pain [29]. The clinical presentation of CRPS remains inconsistent [1] [2] [30] [31] [32] [33]. Resolving how beliefs influence CRPS management is essential.

A weakness of the study is the relatively small sample size with potential bias being represented by the $57 \%$ response rate. Another weakness of the study is the use of Likert scale for measuring the frequency of the physiotherapy interventions that is not formally validated.

The strength is that this study provides the first evidence to represent data across a region, about Physiotherapist beliefs and usual interventions for CRPS patients. The use of self-reporting questionnaires as a valid measure is supported [34]. Future studies should be undertaken to develop validated questionnaires about beliefs around CRPS for Anaesthetists in Pain Management, Physiotherapists, and other health care providers, as well as for patients suffering from CRPS. It is important to determine how these beliefs influence referral, intervention method(s) and patient outcomes.

\section{Conclusion}

CRPS is not common on the South Island of New Zealand. Usual physiotherapy interventions vary widely. Different beliefs exist about the importance of managing the pain experience and the importance of improving function. These reflect the dichotomy seen in current evidence. Education is the most commonly used intervention. Those treating more CRPS patients are more likely to use interventions such as GMI and SMT often (rather than seldom, or not at all). How Anaesthetists in Pain Management and Physiotherapy beliefs about pain management and functional restoration affect CRPS outcomes requires closer scrutiny. 


\section{Conflict of Interest}

The authors declare no conflict of interests regarding the publication of this paper. No funding contribution was received towards selection, extraction or analysis of the data from any source.

\section{References}

[1] Sandroni, P., et al. (2003) Complex Regional Pain Syndrome Type I: Incidence and Prevalence in Olmsted County, a Population-Based Study. Pain, 103, 199-207. https://doi.org/10.1016/S0304-3959(03)00065-4

[2] De Mos, M., et al. (2007) The Incidence of Complex Regional Pain Syndrome: A Population-Based Study. Pain, 129, 12-20. https://doi.org/10.1016/j.pain.2006.09.008

[3] De Mos, M., Sturkenboom, M.C. and Huygen, F.J. (2009) Current Understandings on Complex Regional Pain Syndrome. Pain Practice, 9, 86-99. https://doi.org/10.1111/j.1533-2500.2009.00262.x

[4] Hyatt, K.A. (2010) Overview of Complex Regional Pain Syndrome and Recent Management Using Spinal Cord Stimulation. American Association of Nurse Anaesthetists Journal, 78, 208-212.

[5] Van Eijs, F., et al. (2011) Evidence-Based Interventional Pain Medicine according to Clinical Diagnoses. 16. Complex Regional Pain Syndrome. Pain Practice, 11, 70-87. https://doi.org/10.1111/j.1533-2500.2010.00388.x

[6] Shipton, E.A. (2009) Complex Regional Pain Syndrome-Mechanisms, Diagnosis and Management. Current Anaesthesia \& Critical Care, 20, 209-214. https://doi.org/10.1016/j.cacc.2009.07.012

[7] Quisel, A., et al. (2005) Complex Regional Pain Syndrome Underdiagnosed. Journal of Family Practice, 54, 524-532.

[8] Harden, R.N., et al. (2010) Validation of Proposed Diagnostic Criteria (The "Budapest Criteria") for Complex Regional Pain Syndrome. Pain, 150, 268-274. https://doi.org/10.1016/j.pain.2010.04.030

[9] Harden, R.N., et al. (1999) Complex Regional Pain Syndrome: Are the IASP Diagnostic Criteria Valid and Sufficiently Comprehensive? Pain, 83, 211-219. https://doi.org/10.1016/S0304-3959(99)00104-9

[10] Lunden, L.K., Kleggetveit, I.P. and Palm, E. (2016) Delayed Diagnosis and Worsening of Pain Following Orthopedic Surgery in Patients with Complex Regional Pain Syndrome (CRPS). Scandinavian Journal of Pain, 11, 27-33. https://doi.org/10.1016/j.sjpain.2015.11.004

[11] Catananti, C. and Gambassi, G. (2010) Pain Assessment in the Elderly. Surgical Oncology-Oxford, 19, 140-148. https://doi.org/10.1016/j.suronc.2009.11.010

[12] Pincus, T., Vogel, S., Breen, A., Foster, N. and Underwood, M. (2006) Persistent Back Pain-Why Do Physical Therapy Clinicians Continue Treatment? A Mixed Methods Study of Chiropractors, Osteopaths and Physiotherapists. European Journal of Pain, 10, 67-76. https://doi.org/10.1016/j.ejpain.2005.01.008

[13] Wilson, H.D., Dansie, E.J., Kim, M.S., Moskovitz, B.L., Chow, W. and Turkcorrespondence, D.C. (2013) Clinicians' Attitudes and Beliefs about Opioids Survey (CAOS): Instrument Development and Results of a National Physician Survey. Journal of Pain, 14, 613-627. https://doi.org/10.1016/j.jpain.2013.01.769

[14] Hutchinson, K., Moreland, A.M.E., de Williams, A.C.C., Weinman, J. and Horne, R. (2007) Exploring Beliefs and Practice of Opioid Prescribing for Persistent Non- 
Cancer Pain by General Practitioners. European Journal of Pain, 11, 93-98. https://doi.org/10.1016/j.ejpain.2006.01.003

[15] Moseley, G.L. (2004) Graded Motor Imagery Is Effective for Long-Standing Complex Regional Pain Syndrome: A Randomised Controlled Trial. Pain, 108, 192-198. https://doi.org/10.1016/j.pain.2004.01.006

[16] Daly, A.E. and Bialocerkowski, A.E. (2009) Does Evidence Support Physiotherapy Management of Adult Complex Regional Pain Syndrome Type One? A Systematic Review. European Journal of Pain, 13, 339-358. https://doi.org/10.1016/j.ejpain.2008.05.003

[17] Smart, K.M., Wand, B.M. and O’Connell, N.E. (2016) Physiotherapy for Pain and Disability in Adults with Complex Regional Pain Syndrome (CRPS) Types I and II. Cochrane Database of Systematic Reviews, No. 2, CD010853.

[18] Pleger, B., et al. (2005) Sensorimotor Returning in Complex Regional Pain Syndrome Parallels Pain Reduction. Annals of Neurology, 57, 425-429. https://doi.org/10.1002/ana.20394

[19] De Jong, J.R., Vlaeyen, J.W., Onghena, P., Cuypers, C., den Hollander, M. and Ruijgrok, J. (2005) Reduction of Pain-Related Fear in Complex Regional Pain Syndrome Type I: The Application of Graded Exposure in Vivo. Pain, 116, 264-275. https://doi.org/10.1016/j.pain.2005.04.019

[20] Eccleston, C., et al. (2014) Psychological Therapies for the Management of Chronic and Recurrent Pain in Children and Adolescents. Cochrane Database of Systematic Reviews, No. 5, CD003968.

[21] Stanton-Hicks, M., et al. (1998) Complex Regional Pain Syndromes: Guidelines for Therapy. Clinical Journal of Pain, 14, 155-166. https://doi.org/10.1097/00002508-199806000-00012

[22] Koke, A.J., et al. (2015) Can We "Predict" Long-Term Outcome for Ambulatory Transcutaneous Electrical Nerve Stimulation in Patients with Chronic Pain? Pain Practice, 15, 256-264. https://doi.org/10.1111/papr.12162

[23] Moseley, G.L. and O'Connell, N.E. (2015) Finding the Balance in Complex Regional Pain Syndrome: Expertise, Optimism, and Evidence. Neurology, 84, 19-20. https://doi.org/10.1212/WNL.0000000000001114

[24] Harden, R.N., et al. (2013) Complex Regional Pain Syndrome: Practical Diagnostic and Treatment Guidelines. Pain Medicine, 14, 180-229. https://doi.org/10.1111/pme.12033

[25] Brunner, F., et al. (2010) Disease-Related Knowledge of Patients with Chronic Regional Pain Syndrome. Journal of Rehabilitation Medicine, 42, 458-462. https://doi.org/10.2340/16501977-0539

[26] Norris, S.L., Engelgau, M.M. and Narayan, K.M. (2001) Effectiveness of Self-Management Training in Type 2 Diabetes: A Systematic Review of Randomized Controlled Trials. Diabetes Care, 24, 561-587. https://doi.org/10.2337/diacare.24.3.561

[27] Anandkumar, S. and Manivasagam, M. (2014) Multimodal Physical Therapy Management of a 48-Year-Old Female with Post-Stroke Complex Regional Pain Syndrome. Physiotherapy Theory and Practice, 30, 38-48.

https://doi.org/10.3109/09593985.2013.814186

[28] Pons, T., Shipton, E.A., Williman, J. and Mulder, R.T. (2015) Potential Risk Factors for the Onset of Complex Regional Pain Syndrome Type 1: A Systematic Literature Review. Anesthesiology Research and Practice, 2015, Article ID: 956539.

[29] Sharma, A.M.D., et al. (2009) A Web-Based Cross-Sectional Epidemiological Survey of Complex Regional Pain Syndrome. Regional Anesthesia and Pain Medicine, 34, 
110-115. https://doi.org/10.1097/AAP.0b013e3181958f90

[30] Birklein, F., Kunzel, W. and Sieweke, N. (2001) Despite Clinical Similarities There Are Significant Differences between Acute Limb Trauma and Complex Regional Pain Syndrome I (CRPS I). Pain, 93, 165-171. https://doi.org/10.1016/S0304-3959(01)00309-8

[31] Cossins, L., Okell, R.W., Cameron, H., Simpson, B., Poole, H.M. and Goebel, A. (2013) Treatment of Complex Regional Pain Syndrome in Adults: A Systematic Review of Randomized Controlled Trials Published from June 2000 to February 2012. European Journal of Pain, 17, 158-173. https://doi.org/10.1002/j.1532-2149.2012.00217.x

[32] De Rooij, A.M., et al. (2010) Spontaneous Onset of Complex Regional Pain Syndrome. European Journal of Pain, 14, 510-513. https://doi.org/10.1016/j.ejpain.2009.08.007

[33] Harden, N. (2012) The Diagnosis of CRPS: Are We There Yet? Pain, 153, 11421143. https://doi.org/10.1016/j.pain.2012.02.040

[34] Feise, R.J. and Menke, J.M. (2010) Functional Rating Index: Literature Review. Medical Science Monitor, 16, RA25-RA36.

Submit or recommend next manuscript to SCIRP and we will provide best service for you:

Accepting pre-submission inquiries through Email, Facebook, LinkedIn, Twitter, etc. A wide selection of journals (inclusive of 9 subjects, more than 200 journals) Providing 24-hour high-quality service User-friendly online submission system Fair and swift peer-review system Efficient typesetting and proofreading procedure Display of the result of downloads and visits, as well as the number of cited articles Maximum dissemination of your research work

Submit your manuscript at: http://papersubmission.scirp.org/ Or contact ijcm@scirp.org 